\title{
Liver disease in India
}

\author{
S A BHAVE, A N PANDIT, A M PRADHAN, D G SIDHAYE, A KANTARJIAN, \\ A WILLIAMS, I C TALBOT, AND M S TANNER \\ Department of Paediatrics, King Edward Memorial Hospital, Pune, India; Department of Child Health \\ and Department of Pathology, University of Leicester
}

SUMmARY One hundred and twenty-five children with chronic liver disease were seen in Pune in 13 months. Fifty-nine of them, aged 8-39 months, had Indian childhood cirrhosis histologically diagnosed. Their characteristics included an insidious onset of symptoms, a geographical clustering of cases in rural areas north-east of Pune, a high rate of parental consanguinity and affected siblings, and a very high hepatic copper concentration $(790-6654 \mu \mathrm{g} / \mathrm{g}$ dry weight). Only 8 survived for 6 months, adverse prognostic features being jaundice, ascites, enlargement of the gall bladder, and severe anaemia at presentation. Clinical differentiation from other liver disorders in the same age group was clear in advanced cases but unreliable in earlier cases. Four asymptomatic siblings with hepatomegaly had a benign course. The need for non-invasive methods to diagnose early cases in the community is demonstrated. The other major diagnostic categories were: unresolved hepatitis (12); chronic active hepatitis (7); cryptogenic cirrhosis (6); neonatal hepatitis and biliary atresia (8).

Indian childhood cirrhosis (ICC) and other hepatic disorders are common causes of hospital admission of children in India. ${ }^{1-3}$ Descriptions of ICC from different centres in India however, show differences with respect to its definition, incidence, clinical features, prognosis, and response to treatment with steroids. ${ }^{4-7}$

The recent finding of high concentrations of copper in the liver in ICC has raised hopes of its treatment or prevention..$^{8-15}$ It also increases the need for accurate and early diagnosis of ICC. A prospective study of chronic liver disease in children was therefore started at the King Edward Memorial Hospital, Pune, with four objectives: (1) To study the pattern of chronic liver disease in childhood in this area. (2) To define the clinical features of a group of children with ICC in whom the diagnosis was made upon histological criteria. (3) To measure hepatic copper concentration in a larger group of children than in the previous studies. (4) To provide an epidemiological basis for future studies.

\section{Geography}

Pune, previously Poona, is in the state of Maharashtra, 125 miles inland from Bombay, and is on the Deccan plateau. Its rainfall of approximately $800 \mathrm{~mm}$ falls between June and August. Pune is an industrial, administrative, and university city and conurbation, pupulation 1.69 million (1981 census) The districts of Pune, and surrounding districts of Ahmednagar, Nasik, Sholapur, Sangli, and Kolhapurôㄱ had a combined population of 17.7 million in the 1971 census and are predominantly agricultural, Marathi-speaking areas. ${ }^{16-17}$

\section{Methods}

Children presented to the King Edward Memorial Hospital either directly or by referral from two other hospitals in Pune, or paediatricians in surrounding towns. No attempt was made to ascertain all cases of paediatric chronic liver disease.

The study began on 1 February and admission required one of the following criteria:

(1) Jaundice for at least 4 weeks.

(2) Either-hepatomegaly, the liver edge being more than $4 \mathrm{~cm}$ below the costal margin, for longer than 4 weeks

or-a history of abdominal distension for longer than 4 weeks, with firm hepatomegaly on examination.

(3) Ascites for longer than 4 weeks.

(4) A liver biopsy showing cirrhosis.

Clinical features, haematological values, and liver function tests were recorded on a standard pro forma. Liver biopsy was performed if coagulation studies permitted using the Trucut disposable needle 
(Travenol) under local anaesthesia with intravenous diazepam. A part of each biopsy was used for histological assessment independently by two pathologists (A M P, I C T) neither of whom knew the clinical details. Histological diagnosis of ICC required the following criteria: (1) Widespread hepatocyte ballooning and necrosis, with presence of hyalin inclusions. (2) Pericellular intralobular fibrosis. (3) Absence of fatty infiltration.

Sections were also stained with rhodanine, to demonstrate copper, and with orcein, to demonstrate copper-associated protein.

A second part of the biopsy was freeze-dried in a copper-free container, transported to Leicester, and assayed for copper using a Pye Unicam atomic absorption spectrophotometer with electrothermal atomisation. Liver tissue from a group of infants and children who died from non-hepatic causes was similarly assayed.

Follow-up of children who were able to leave hospital was effected by return outpatient visits, and by home visits by a medical and paramedical team member. Children with ICC received supportive treatment for anaemia, vitamin deficiencies, intercurrent infection, and eventual hepatocellular failure and bleeding. Steroids were not used. Thirty children with ICC entered a controlled trial of d-penicillamine, details of which will be presented subsequently. Children with other hepatic disorders received treatment as appropriate.

\section{Results}

One hundred and twenty-five children with chronic liver disease were seen in 13 months, representing $9 \%$ of ward admissions. The number of referred cases increased during the study period, children with chronic liver disease having comprised $3 \%$ of ward admissions in the two previous years.

Percutaneous liver biopsies were obtained in 101 children, in 2 of whom biopsy complications occurred. One child developed hypotension, and one had haemobilia which ceased spontaneously. Liver biopsies at necropsy were permitted in 11 other children, although in no case was a full necropsy permitted. Statistical analysis was confined to the 112 children in whom a histological diagnosis was available (Table 1).

\section{Indian childhood cirrhosis}

Children with ICC formed the largest (53\%) group. Their ages ranged from 8 to 39 (mean 18.1) months while those with other hepatic disorders ranged from 2 weeks to 18 years (Fig. 1). Boys outnumbered girls in both groups (ICC $\mathrm{M}: \mathrm{F}=3.9: 1$; other $\mathrm{M}: \mathrm{F}=2 \cdot 5: 1)$.

Parental consanguinity was appreciably more common among children with ICC than among those with other disorders (Table 2). After excluding first-born children, $43 \%$ of cases of ICC had a sibling or first-cousin with an illness clinically diagnosed as ICC; this proportion was significantly higher than the proportion of children with other hepatic disorders who had a sibling or first-cousin with any kind of liver disease $(15 \%)$.

Most of the children with ICC came from villages or towns outside Pune, and tended to derive from an area to the north-east of Pune. Discussions with doctors in towns around Pune indicated that this

Table 1 Histological diagnoses and hepatic copper concentration in children with chronic liver disease

\begin{tabular}{|c|c|c|c|c|c|}
\hline \multirow[t]{2}{*}{ Diagnosis } & \multirow[t]{2}{*}{ Number } & \multicolumn{4}{|c|}{ Hepatic copper concentration $(\mu g / g d r y$ weight) } \\
\hline & & Number assayed & Mean & $S D$ & Values or range \\
\hline $\begin{array}{l}\text { Indian childhood cirrhosis } \\
\text { 'Putative early ICC' }\end{array}$ & $\begin{array}{r}59 \\
4\end{array}$ & $\begin{array}{r}53 \\
4\end{array}$ & $\begin{array}{r}1929 \\
200\end{array}$ & 939 & $\begin{array}{l}790-6654 \\
35,41,340,384\end{array}$ \\
\hline $\begin{array}{l}\text { Neonatal hepatitis } \\
\text { Extrahepatic biliary atresia }\end{array}$ & $\begin{array}{l}3 \\
5\end{array}$ & $\begin{array}{l}1 \\
4\end{array}$ & $\begin{array}{l}206 \\
294\end{array}$ & & $121,258,353444$, \\
\hline $\begin{array}{l}\text { Unresolved hepatitis } \\
\text { Chronic active hepatitis }\end{array}$ & 12 & 10 & 37 & 22 & 12-92 \\
\hline $\begin{array}{l}\text { Wilson's disease } \\
\text { Other } \\
\text { Other cirrhosis } \\
\text { Venous outflow obstruction }\end{array}$ & $\begin{array}{l}2 \\
5 \\
6 \\
3\end{array}$ & $\begin{array}{l}2 \\
3 \\
4\end{array}$ & $\begin{array}{l}888 \\
113 \\
259\end{array}$ & & $\begin{array}{l}311,1465 \\
11,56,282 \\
21-635\end{array}$ \\
\hline $\begin{array}{l}\text { Storage/infiltration } \\
\text { Minor changes } \\
\text { Total }\end{array}$ & $\begin{array}{r}5 \\
8 \\
112\end{array}$ & $\int_{95}^{14}$ & 108 & 170 & $17-636$ \\
\hline $\begin{array}{l}\text { Controls } \\
\begin{array}{l}\text { Age 0-1 month } \\
6-12 \text { months } \\
>1 \text { year }\end{array}\end{array}$ & & $\begin{array}{r}15 \\
5 \\
7\end{array}$ & $\begin{array}{r}274 \\
42 \\
45\end{array}$ & $\begin{array}{r}212 \\
36 \\
34\end{array}$ & $\begin{array}{c}17-612 \\
8-93 \\
13-118\end{array}$ \\
\hline
\end{tabular}




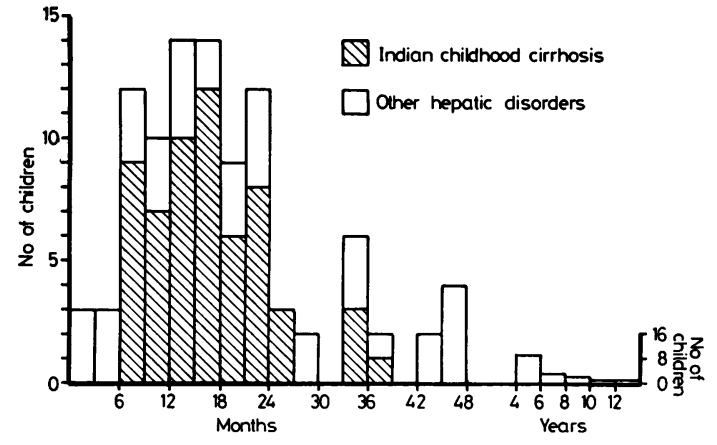

Fig. 1 Age distribution of 112 children presenting to hospital in Pune with chronic liver disease.

distribution accurately reflected the true incidence of the disease, ICC being viewed as a common problem in the districts of Pune, Ahmed Nagar, and Sholapur, but as rare in the district of Sangli. By contrast, children with other hepatic disorders were largely derived from urban Pune.

\section{Clinical features of ICC}

Onset. Three patterns of onset of symptoms were described by parents:

(1) The majority (47 children) had an insidious onset of abdominal distension, followed by fever, malaise, then jaundice.

(2) In $5(8 \%)$ children an episode of jaundice $2-9$ months before admission was said to be followed by fever, malaise, distension, and return of jaundice.

(3) Seven (12\%) children were said to have had a sudden onset of abdominal distension, fever, jaundice, and malaise 2-4 weeks before admission, and to have been previously well. Questioning suggested that these children had, in fact, had abdominal distension before the acute episode, and that these were children similar to (1) presenting at a later stage.

Table 2 Family history

\begin{tabular}{llll}
\hline & $\begin{array}{l}\text { Indian } \\
\text { childhood } \\
\text { cirrhosis } \\
(n=59)\end{array}$ & $\begin{array}{l}\text { Other } \\
\text { hepatic } \\
\text { disorders } \\
(n=53)\end{array}$ & $P$ \\
\hline $\begin{array}{l}\text { Consanguinuity } \\
\text { Number excluding } \\
\text { first born }\end{array}$ & 10 & 1 & $0.014^{*}$ \\
$\begin{array}{l}\text { Number with affected } \\
\text { sibling or first cousin }\end{array}$ & 18 & 39 & $0 \cdot 01^{*}$ \\
\hline
\end{tabular}

*Fisher's exact probability test.

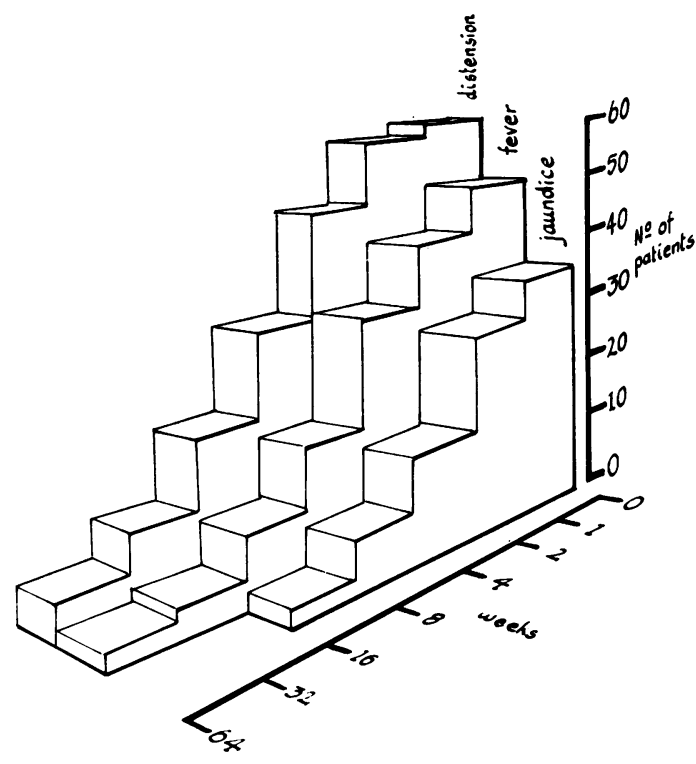

Fig. 2 Duration of abdominal distension, fever, and jaundice noticed by parents before presentation to hospital in 59 children with Indian childhood cirrhosis.

Presenting symptoms. The symptom precipitating presentation to hospital was: abdominal distension ${ }^{+}$ in $40 \%$, persistent fever in $24 \%$, a lump in the belly (the hard enlarged liver) in $12 \%$, and jaundice in $7 \%$. The frequency and duration of the three most common symptoms is shown in Fig. 2.

Physical examination. On examination hepatomegaly was present in all cases of ICC, the liver having a firm or hard consistency and a strikingly sharp edge in most cases. Its surface was smooth in $75 \%$ and nodular in $25 \%$. Splenomegaly was found in $97 \%$, ascites in $63 \%$, jaundice in $53 \%$, and dilated abdominal wall veins in $47 \%$. An unexpected feature was the presence of a palpable gall bladder in 4 children at presentation, and in 11 further cases during its course. These children were generally ill and febrile, with conjugated hyperbilirubinaemia (total bilirubin $181 \pm 19 \mu \mathrm{mol} / \mathrm{l}$; conjugated bilirubin $87 \pm 68 \mu \mathrm{mol} / \mathrm{l}$ ), and a poor prognosis; death occurred in 10 children 3 to 65 days after the sign was noted. In 2 children, treatment with antibiotics (ampicillin, gentamicin, and metronidazole) was associated with disappearance of the palpable gall bladder. ${ }^{18}$

Prognosis. One child with ICC was lost to follow-up. The survival of the remaining 58 is shown in Fig. 3. 


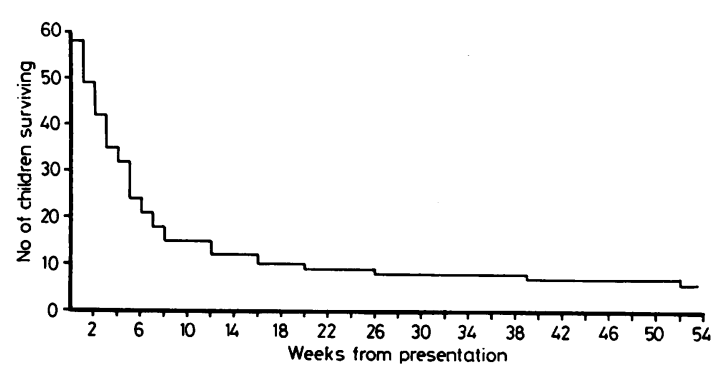

Fig. 3 Length of survival after presentation of 58 children with Indian childhood cirrhosis.

No significant difference in survival was seen in penicillamine-treated cases. Forty-five per cent died within 4 weeks, $74 \%$ within 8 weeks, and $86 \%$ within 6 months. The mode of death in all cases was hepatocellular failure, precipitated in some children by intercurrent infection or gastrointestinal haemorrhage. After one year, only 6 children survived. Of these, 3 died in the second year ( 1 from a measles encephalitis), while the remaining 3 remain alive in good health but with firm hepatomegaly 13-20 months after presentation.

Survival was significantly inversely correlated with the presence of jaundice and ascites at presentation, but not with age at presentation, duration of history, ponderal index (weight/height ${ }^{2}$ ), or size of liver or spleen.

Laboratory investigations. Laboratory investigations were compared in children with ICC and those with other hepatic disorders who were in the same age range (Table 3). Haemoglobin values were lower in ICC, and were significantly correlated with survival $(r=0.33, P<0.02)$ and inversely with serum bilirubin $(r=-0.46, P<0.001)$. Total bilirubin, serum alanine transaminase, and prothrombin time showed greater

Table 3 Laboratory investigations in children with Indian childhood cirrhosis and in children of similar age with other hepatic disorders

\begin{tabular}{lccccc}
\hline & $\begin{array}{l}\text { Indian } \\
\text { childhood } \\
\text { cirrhosis } \\
(n=59)\end{array}$ & $\begin{array}{l}\text { Other } \\
\text { hepatic } \\
\text { disorders } \\
(n=25)\end{array}$ & $t$ & $P$ & \\
\hline Hb g/dl & $7.6 \pm 2.0$ & $8.9 \pm 3.1$ & 2.15 & $<0.02$ \\
$\begin{array}{l}\text { Total bilirubin } \\
(\mu m o l / 1)\end{array}$ & $75 \pm 75$ & $29 \pm 41$ & 2.67 & $<0.02$ \\
$\begin{array}{l}\text { Serum alanine } \\
\text { transaminase IU/1 }\end{array}$ & $126 \pm 80$ & $48 \pm 48$ & 4.08 & $<0.001$ \\
$\begin{array}{c}\text { Prothrombin time } \\
\text { before vitamin K- } \\
\text { seconds prolonged }\end{array}$ & $9.5 \pm 8.2$ & $4.8 \pm 4.2$ & 2.28 & $<0.02$ \\
\begin{tabular}{l} 
Albumin \\
\hline
\end{tabular} & $4.02 \pm 0.60$ & $4.25 \pm 2.35$ & 0.67 & $>0.5$ \\
\hline
\end{tabular}

abnormalities in ICC, while serum albumin concentration was similar in both groups, and showed no correlation with ponderal index.

\section{Other hepatic disorders}

Putative ICC. Four infants, aged 5-20 months, were referred because each had at least one sibling who had died from histologically proved ICC, and had been found to have firm hepatomegaly. Liver function tests were normal. In each case, liver histology showed preservation of normal architecture, but the presence of ballooned, vacuolated hepatocytes. These infants have been followed up for 12-20 months, and remain clinically well.

Obstructive jaundice in infancy. Of 8 infants with cholestatic jaundice, 5 had extrahepatic biliary atresia diagnosed at laparotomy in two, at laparoscopy in two, or at limited necropsy examination in one. Their ages ranged from 1.5 to 11 (mean 5.7) months, and in one infant aged 4 months with a 'correctable' atresia, bile drainage was achieved surgically. Only 3 cases of neonatal hepatitis presented to hospital. Of these, one died, and another, who had at age 6 weeks developed jaundice and a cerebral haemorrhage, presented at age 8 months with continuing liver disease and hemiplegia.

Chronic active hepatitis and Wilson's disease. Two cases of Wilson's disease were seen. These, and 2 of 5 further cases of chronic active hepatitis, already had cirrhosis at presentation. Evidence of hepatitis B infection was found in one case.

Unresolved hepatitis. In 12 children, aged $1 \cdot 2$ to 4 years, liver biopsy showed features of an unresolved hepatitis, without piecemeal necrosis or disruption of the limiting plate. Clinical differentiation from ICC was difficult in these cases. Eight had had a hepatic illness within the previous 8 weeks, and liver biopsy was indicated because of persisting significant hepatosplenomegaly. Four had had abdominal distention for 2-8 months. The most helpful physical sign in distinguishing these children from those with ICC was the liver consistency, which was firm rather than hard, and the liver edge which was rounded rather than sharp.

Other cirrhoses. Six children had biopsies showing cirrhosis without the features of ICC or chronic active hepatitis. The youngest of these, aged 13 months, had 2 siblings who had died in infancy from an illness clinically diagnosed as ICC. He had presented at age 5 months with a hepatic illness but, 
despite continued hepatosplenomegaly and abnormal liver function tests, he subsequently remained clinically well.

Two boys, aged 5 years, presented with a 2-week history of abdominal pain and jaundice progressing to acute hepatic failure and death; cirrhosis was an unexpected finding at necropsy.

The remainder, aged 3-5 years, had a compensated inactive cirrhosis.

None had $\alpha$-1-antitrypsin deficiency or hepatitis B infection.

Venous outflow obstruction. Two boys, aged 3 and 5 years, presented with a 2-week history of abdominal distension, fever, and vomiting, and had clinical features suggestive of Budd-Chiari syndrome. Liver biopsy showed severe centrizonal congestion and central vein dilatation. Both died. In a third child, aged 7 months, with a biopsy suggestive of venous outflow obstruction, ascites resolved and he survived. No cardiovascular abnormalities were demonstrated.

\section{Hepatic copper concentration}

Hepatic copper concentration was measured in 95 children with chronic liver disease, and in 27 controls (Table 1). In 15 neonates dying from non-hepatic causes, values were higher than in later infancy or older children.

Fifty-three children with ICC all had very high values, range 790 to $6654 \mu \mathrm{g} / \mathrm{g}$ dry weight. In all of these biopsies, orcein and rhodanine staining showed heavy granular copper and copper-associated deposition.

Two of the 4 infants with 'putative early ICC' had raised hepatic copper concentrations and scanty orcein staining, whereas 2 had normal copper concentrations.

Values exceeding $250 \mu \mathrm{g} / \mathrm{g}$ dry weight were also seen in Wilson's disease, in 1 of 3 cases of chronic active hepatitis, in 3 of 4 cases of extra hepatic biliary atresia, and in 1 child with cryptogenic cirrhosis. Hepatic copper concentration correlated with a subjective quantitation of grade of orcein and rhodanine staining in all cases except the 5-year-old boy with Wilson's disease in whom orcein staining was scanty.

\section{Discussion}

The histological features of ICC clearly distinguish it from other hepatic disorders, and it was felt important in this study to identify a group of children with ICC on histological criteria. Some authors have preferred to widen the definition. In the classification of Aikat et al. ${ }^{4}$ for example, chronic active hepatitis was called ICC type 1 ; ICC as described in this paper as ICC type 2; cryptogenic cirrhosis as ICC type 3 ; and macronodular cirrhosis with steato-necrosis as ICC type 4. Inclusion of types 1, 3, or 4 of Aikat et al., or of children clinically diagnosed as suffering from ICC but actually having an unresolved hepatitis, would markedly have altered the survival statistics in the present study.

While the present data do not allow an estimate of the prevalence of paediatric liver disease in Pune children, it is clear that ICC, as the most common liver disorder in 1- to 5-year-old children, contributes significantly to mortality in that age group. The pathogenetic features restricting ICC to the age range 8-39 months remain to be elucidated, as does the difference from other series in which children up to 12 years have been included.

While boys with ICC outnumbered girls, the similar male predominance in other hepatic disorders $N$ suggests that this may be caused by the referral $\cong$ pattern. Parekh and Patel, ${ }^{19}$ in their field study, found that ICC affects the sexes equally. It may be suspected, therefore, that there is a population of infant girls with ICC dying at home undiagnosed.

The clustering of ICC within sibships may equally well be due to common environment or common genes. However, the high rate of parental cong sanguinity supports the contention of Agarwa et al. ${ }^{20}$ of a genetic role in its aetiology. Restriction of ICC to the Asian subcontinent suggests that environmental factors are also important. This study has identified areas of high incidence of ICC to the north-east of Pune, scrutiny of which is in progress in an attempt to elucidate these factors.

The onset of ICC is generally described as insidious in $75 \%$, and hepatitic in $25 \% .^{56}$ Only $8 \%$ of the present group had a history of a hepatitic illness in the previous 9 months. In a further $12 \%$, a sudden onset of jaundice, fever, and malaise precipitating presentation was felt to be a terminal deterioration of an established disease. The generally 3 . insidious onset of ICC partly explains the advanced $\delta$ stage of the disease at presentation. Many parents however, describe symptoms which have been $O$ present for as long as 3-6 months and other reasons for delay in seeking medical advice were apparent. Such reasons included: the rural rather than urban origin of cases; the frequency of abdominal dis- $N$ tension as a symptom of more benign disorders; $N$ parental distrust of doctors which led them to seek N other healers, as demonstrated by the frequency of branding marks of varying ages on the abdomen; the fear of hospitals fostered by the death of a previous $\frac{0}{\Phi}$ sibling.

The advanced stage of ICC at presentation was demonstrated by the poor survival. Six months 
after presentation, only $14 \%$ were still alive. These survivors however, had an excellent chance of being alive after 6 further months. Their continued follow-up will be of considerable interest. Do they contribute to the group of children presenting with cryptogenic cirrhosis later in childhood? If so, have other older children with cryptogenic cirrhosis actually had a milder ICC which remained undiagnosed?

Clearly, any therapeutic progress in this disease depends on much earlier identification of cases, seeking them out in their villages rather than waiting for them in city hospitals and this requires simple diagnostic methods. A clinical diagnosis was correctly made in the majority of the 59 children with ICC, the stony hard consistency and very sharp edge of the liver being pathognomonic. Wrong diagnoses of two kinds were made, however: several of the younger children with ICC were felt to be 'too well' and to have insufficiently hard hepatomegaly; conversely, several older children, clinically diagnosed as 'early ICC' had histological features of unresolved hepatitis. Thus, clinical diagnosis is reliable only when it is far too late to be valuable. Standard laboratory tests were also unhelpful, although as a group, children with ICC had lower haemoglobin concentrations and higher transaminase values. Liver biopsy currently therefore, remains essential for diagnosis. While no serious complications of biopsy occurred in this series, the need for this procedure is the largest practical and ethical obstacle to a search in the community for early cases. Hopes of a non-invasive diagnostic method currently rest on the abnormal copper storage found in ICC.

The present series corroborates the earlier finding of a grossly increased hepatic concentration in ICC, the value of $6654 \mu \mathrm{g} / \mathrm{g}$ dry weight being the highest value recorded in human liver. Measurements in controls show no significant difference from western reports. Values above $800 \mu \mathrm{g} / \mathrm{g}$ clearly distinguished ICC from other paediatric disorders with the exception of Wilson's disease. A striking and previously described feature of the 5-year-old child with Wilson's disease was the failure of rhodanine or orcein to demonstrate the excess copper or copper-associated protein in liver sections. ${ }^{21}{ }^{22}$ In all other children assessments of copper biochemically and histologically were in concordance.

The opportunity to compare extra hepatic biliary atresia in Indian children with ICC demonstrated that cholestasis was unlikely to explain the hepatic copper storage in ICC, the values in extrahepatic biliary atresia resembling those found in western reports. ${ }^{23}$

Of the 4 younger siblings of children with ICC who had hepatomegaly and minor histological abnormalities, 2 had raised hepatic copper concentrations and all have remained well. Two other reports of larger numbers of asymptomatic siblings have found that very few ${ }^{19}$ or none ${ }^{24}$ proceed to ICC. Further large studies are necessary to determine whether these siblings have a forme fruste of ICC; whether, for example, they are affected by only one of two or more aetiological mechanisms required to cause the disease; and what is their long-term prognosis.

Although the numbers of cases in other diagnostic categories were small, several features were apparent.

The late referral of babies that conjugated hyperbilirubinaemia resulted in few babies with neonatal hepatitis coming to hospital. If the pattern of neonatal hepatitis in India resembles that in the $\mathrm{UK},{ }^{25}$ most such idiopathic hepatitides will recover spontaneously at home.

The 3 cases of Budd-Chiari syndrome represented a group which requires further investigation.

Chronic hepatitides were common. As in the UK, ${ }^{26}$ chronic active hepatitis was likely to have progressed to cirrhosis by the time of presentation to hospital. In a population where infectious hepatitis is common, suspicion of chronic active hepatitis is low and immunological methods for autoantibodies are generally not used. As a treatable liver disorder, chronic active hepatitis deserves greater attention.

We thank the Wellcome Trust for generous financial support, the paediatricians who referred cases, H R Patel for technical assistance, and Mrs Anne Gilbert for secretarial help.

\section{References}

1 Jelliffe D B, Bras G, Mukherjee K L. Veno-occlusive disease of the liver, and Indian childhood cirrhosis. Arch Dis Child 1957; 32: 369-85.

2 Chandra R K. Indian childhood cirrhosis-clinical, biochemical, genealogical, histomorphological, and immunological observations. Med Chir Dig 1974; 3: 63-8.

3 Nayak N C, Ramalingaswami V. Indian childhood cirrhosis. Clin Gastroenterol 1975 ; 4: 333-49.

4 Aikat B K, Bhattacharya T, Walia B N S. Morphological features of Indian childhood cirrhosis: the spectrum of changes and their significance. Indian J Med Res 1974; 62 : 953-63.

5 Raju V B, Sundaravalli N, Sriramachari S. Indian childhood cirrhosis-some observations on the pathology and etiology. Indian J Pediatr 1980; 47: 543-7.

6 Raju V B, Sundaravalli N, Sriramachari S. Indian childhood cirrhosis: clinical features, prognosis, and treatment. Indian J Pediatr 1980; 47: 537-41.

7 Bhagwat A G, Walia B N S. Indian childhood cirrhosis: a commentary. Indian J Pediatr 1980; 48: 433-7.

8 Portmann B, Tanner M S, Mowat A P, Williams R. Orcein positive liver deposits in Indian childhood cirrhosis. Lancet 1978; i: 1338-40.

- Tanner M S, Portmann B, Mowat A P, Williams R. Indian childhood cirrhosis presenting in Britain with

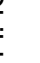


orcein positive deposits in liver and kidney. $\mathrm{Br}$ Med $\mathrm{J}$ 1978; ii: 928-9.

10 Tanner M S, Portmann B, Mowat A P, et al. Increased hepatic copper concentration in Indian childhood cirrhosis. Lancet 1979; i: 1203-5.

11 Popper H, Goldfischer S, Sternlieb I, Nayak N C, Madhavan T V. Cytoplasmic copper and its toxic effects: studies in Indian childhood cirrhosis. Lancet 1979; i: 1205-8.

12 Tanner M S, Portmann B. Indian childhood cirrhosis. Arch Dis Child 1981; 56: 4-6.

13 Tanner M S. Copper and Indian childhood cirrhosis. Indian J Pediatr 1980; 47: 467-70.

14 Portmann B, Walker-Smith J A, Tanner M S. Letter: Wilson's disease, chronic copper poisoning, or Indian childhood cirrhosis? Arch Dis Child 1980; 55: 163-4.

15 Marwaha N, Nayak N C, Roy S, Kalra V, Ghai O P. The role of excess hepatic copper in the evolution of Indian childhood cirrhosis. Indian J Med Res 1981; 73: 395-403.

16 Central Statistical Organisation. Statistical abstract. India. India: Ministry of Planning, Government of India, 1972.

17 India. The Far East and Australasia 1981-82. London: Europa Publications, 1981: 428-98.

18 Pandit A N, Bhave S A, Sidhaye D G, Datar G V. Palpable gall bladder in Indian childhood cirrhosis. Indian Pediatr 1981 ; 18: 905-8.

19 Parekh S R, Patel B D. Epidemiological survey of Indian childhood cirrhosis. Indian Pediatr 1972; 9: 431-9.
20 Agarwal S S, Lahori U C, Mehta S K, Smith D G, Bajpai P C. Inheritance of Indian childhood cirrhosis. Hum Hered 1979; 29: 82-9.

21 Evans J, Newman S P, Sherlock S. Observations on copper associated protein in childhood liver disease. Gut $1980 ; 21$ : 970-6.

22 Anonymous. Wilson's disease and copper-associated protein. Lancet 1981 ; i: 644-6.

23 Ohi R, Lilly J R. Copper kinetics in infantile hepatobiliary disease. J Pediatr Surg 1980; 4: 509-12.

24 Nayak N C, Marwaha N, Kalra V, Roy S, Ghai O P. The liver in siblings of patients with Indian childhood cirrhosis: a light and electron microscopic study. Gut 1981; 22: 295-300.

25 Mowat A P, Psacharopoulos H T, Williams R. Extrahepatic biliary atresia versus neonatal hepatitis. Review of 137 prospectively investigated infants. Arch Dis Child $1976 ; 51: 763-70$.

26 Vegnente A, Larcher V, Portmann B, Mowat A P. Chronic active hepatitis (CAH) in childhood-a plea for early diagnosis (abstract). Pediatr Res 1981; 15 : 1196.

Correspondence to Dr M S Tanner, Department of Child Health, Clinical Sciences Building, Leicester Royal Infirmary, P O Box 65, Leicester LE2 7LX.

Received 7 September 1982 